\title{
PHLPP2 is a novel biomarker and epigenetic target for the treatment of vitamin $\mathrm{C}$ in pancreatic cancer
}

\author{
LIN CHEN $^{1 *}$, HUAN SONG $^{1 *}$, ZHONGGUANG LUO $^{1 *}$, HAOSHU CUI $^{1 *}$, \\ WANWEI ZHENG ${ }^{1}$, YAO LIU ${ }^{1}$, WENSHUAI LI ${ }^{1}$, FEIFEI LUO ${ }^{1,2}$ and JIE LIU ${ }^{1}$ \\ ${ }^{1}$ Department of Digestive Diseases of Huashan Hospital and Institutes of Biomedical Sciences, Fudan University, \\ Shanghai 200040; ${ }^{2}$ Biotherapy Research Center, Fudan University, Shanghai 200032, P.R. China
}

Received September 17, 2019; Accepted February 7, 2020

DOI: $10.3892 /$ ijo.2020.5001

\begin{abstract}
Epigenetic dysregulations are closely associated with the development of pancreatic ductal adenocarcinoma (PDAC), which is one of the most aggressive malignancies and currently has limited treatment options. Vitamin C (VC), an epigenetic mediator, exerts antitumor effects on several types of cancer. However, the clinical application of $\mathrm{VC}$ is limited, particularly in PDAC. Thus, to investigate the antitumor effects and explore the potential clinical application of $\mathrm{VC}$ in PDAC, the survival of patients from The Cancer Genome Atlas database were analyzed, and proliferation, apoptosis and migration assays were performed in the present study. It was first established that high expression levels of the sodium-dependent VC transporter 2, a critical VC transporter, predicted a good prognosis in patients with pancreatic adenocarcinoma. It was further confirmed that VC directly inhibited proliferation, induced apoptosis and suppressed migration of human pancreatic cancer cells. Global 5-hydroxymethylcytosine $(5 \mathrm{hmC})$ content was significantly upregulated in pancreatic cancer cells following $\mathrm{VC}$ treatment, predominantly relying on ten-eleven translocation 2. Furthermore, VC could specifically increase $5 \mathrm{hmC}$ levels at the promotor region on $\mathrm{PH}$ domain leucine-rich repeat protein phosphatase 2 (PHLPP2) and enhance PHLPP2 expression levels. When PHLPP2 expression levels were knocked down, VC was able to partially overcome the inhibition of pancreatic cancer cells. These results illustrated a novel and precise mechanism of action of epigenetic alterations that
\end{abstract}

Correspondence to: Dr Jie Liu or Dr Feifei Luo, Department of Digestive Diseases of Huashan Hospital and Institutes of Biomedical Sciences, Fudan University, 12 Middle Wulumuqi Road, Shanghai 200040, P.R. China

E-mail: jieliu@fudan.edu.cn

E-mail: feifeiluo@fudan.edu.cn

*Contributed equally

Key words: pancreatic ductal adenocarcinoma, $\mathrm{PH}$ domain leucine-rich repeat protein phosphatase 2, sodium-dependent VC transporter 2, ten-eleven translocation 2, vitamin C underly the inhibition of $\mathrm{VC}$ in pancreatic cancer, and emphasized that PHLPP2 may be a new biomarker and epigenetic target for the clinical treatment of VC in PDAC.

\section{Introduction}

Pancreatic ductal adenocarcinoma (PDAC) is one of the most common types of primary carcinoma of the pancreas, with $\sim 56,770$ new cases and 45,750 mortalities annually in the USA in 2019 (1). The 5-year survival rate remains at $6 \%$ due to late diagnosis and therapy resistance (2). Therefore, it is necessary to investigate appropriate methods for the diagnosis and treatment of PDAC.

Vitamin C (VC), a strong reducing agent and antioxidant, can be oxidized into dehydroascorbic acid (DHA) when in solution (3). Human cells uptake VC and DHA through sodium-dependent VC transporters (SVCTs) and glucose transporters (GLUTs) (4,5). The high-affinity SVCT2 transporter is ubiquitously expressed and more commonly expressed in cancer cells compared with SVCT1 (6). Based on its chemical properties, VC functions as a cofactor of $\mathrm{Fe}(\mathrm{II})$ and is part of the $\alpha$-ketoglutarate-dependent dioxygenase family, participating in biological processes, including collagen synthesis, regulation of hypoxia-inducible factor stability, and methylation of DNA and histones $(7,8)$.

Epigenetics, such as DNA methylation, refers to heritable alterations in gene expression without changes in the DNA sequence (9). The ten-eleven translocation (TET) protein family members are considered key enzymes for DNA demethylation, which can oxidize 5-methylcytosine $(5 \mathrm{mC})$ to 5 -hydroxymethylcytosine $(5 \mathrm{hmC})$ in a $\mathrm{Fe} 2^{+} / \alpha$-ketoglutarate dependent reaction $(10,11)$. There are three TET proteins, TET1, 2 and 3, among which TET2 is the most commonly mentioned member and has been investigated in previous tumor studies $(12,13)$. Previous studies have shown that VC is indispensable for TET enzymes to maintain catalytic activity (14-16). VC can promote DNA demethylation through TETs, particularly TET2, to upregulate the expression levels of tumor suppressor genes in tumor cells and achieve an antitumor effect in leukemia and solid tumors, including liver, ovarian and kidney cancer (17-20).

Considering the involvement of VC in epigenetic modifications and the key role of epigenetic dysregulation in the 
development of PDAC, VC treatment may be a promising strategy for PDAC therapy. Although numerous studies have reported the antitumor activity of $\mathrm{VC}$ treatment both in vitro and in vivo (21-25), previous clinical trials and case studies concerning PDAC have failed to confirm a clinical efficacy of VC treatment $(26,27)$. Furthermore, VC treatment has failed to demonstrate an improvement in patient quality of life and chemosensitivity (28-31). This may indicate that VC treatment does not conform to all patients and that biomarkers are required to identify the sensitivity of $\mathrm{VC}$ treatment in individual patients. Therefore, it is essential to understand the role of VC treatment in PDAC and to precisely investigate the underlying mechanisms of action, which would be beneficial to the development of alternative therapies or to allow for the proper selection of patients for effective $\mathrm{VC}$ treatment in PDAC.

The present study provided the first evidence that SVCT2 predicted good prognoses in patients with PDAC. VC directly inhibited the viability of human pancreatic cancer cells in vitro. Furthermore, VC promoted DNA demethylation of the $\mathrm{PH}$ domain leucine-rich repeat protein phosphatase 2 (PHLPP2) promoter to upregulate the expression levels of PHLPP2 and exert a tumor inhibitory effect. As such, the present study illustrated a new mechanism for VC in the suppression of pancreatic cancer, and indicated that PHLPP2 may be a biomarker and an epigenetic target for the clinical application of VC in PDAC.

\section{Materials and methods}

Cell culture and reagents. Capan-1 (a poorly-differentiated primary PDAC cell line) and PANC-1 (a well-differentiated metastasis PDAC cell line) were purchased from The Cell Bank of Type Culture Collection of Chinese Academy of Sciences. The PDAC cell lines were cultured in DMEM (Gibco; Thermo Fisher Scientific, Inc.) supplemented with $10 \%$ fetal bovine serum (FBS; Gibco; Thermo Fisher Scientific, Inc.) and $50 \mathrm{IU} / \mathrm{ml}$ penicillin/streptomycin (Gibco; Thermo Fisher Scientific, Inc.) at $37^{\circ} \mathrm{C}$. VC (Sigma-Aldrich; Merck KGaA) was diluted in PBS.

Cell viability assay. Capan-1 and PANC-1 cells were seeded in a 96-well plate at a density of $1 \times 10^{4}$ cells/well. Following $24 \mathrm{~h}$ of incubation, the cells were treated with 0 , $0.5,1,2,4$ or $8 \mathrm{mM} \mathrm{VC}$ for $48 \mathrm{~h}$ at $37^{\circ} \mathrm{C}$. Subsequently, cell viability was evaluated using Cell Counting Kit-8 (CCK-8; Dojindo Molecular Technologies, Inc.), according to the manufacturer's instructions. Absorbance was measured at $450 \mathrm{~nm}$ using an Infinite M200 PRO microplate reader (Tecan Group, Ltd.).

Colony formation assay. Capan-1 and PANC-1 cells were seeded in a 6 -well plate $\left(1 \times 10^{3} /\right.$ well) and incubated for $24 \mathrm{~h}$, followed by treatment with $0.5 \mathrm{mM} \mathrm{VC}$ at $37^{\circ} \mathrm{C}$ for a further $48 \mathrm{~h}$. Following incubation in fresh medium for 10 days, the cells were washed with PBS, fixed using $4 \%$ paraformaldehyde for $15 \mathrm{~min}$ at room temperature and stained using $0.01 \%$ crystal violet for $20 \mathrm{~min}$ at room temperature. Subsequently, the cell colonies were imaged and counted in the whole view using an inverted light microscope (magnification, $\mathrm{x} 40$ ).
Isolation of peripheral blood mononuclear cells (PBMCs). Blood samples from 5 patients with PDAC, including 3 males and 2 females (median age, 61.40 years; age range, 55 to 61 years), were obtained in November 2019 from Huashan Hospital, Fudan University (Shanghai, China). Human blood ( $\sim 8 \mathrm{ml}$ ) was added slowly into $4 \mathrm{ml}$ Percoll (GE Healthcare). The cells were separated by gradient centrifugation at $4^{\circ} \mathrm{C}$ for $20 \mathrm{~min}$ at $850 \mathrm{x} \mathrm{g}$. The upper phase (buffer and plasma) was discarded and the PBMCs were collected. The cells were washed using PBS and centrifuged for $5 \mathrm{~min}$ at $500 \mathrm{x}$ g at $4^{\circ} \mathrm{C}$. The remaining red blood cells were lysed using ACK Lysing Buffer (Gibco; Thermo Fisher Scientific, Inc.), washed in PBS and centrifuged for $5 \mathrm{~min}$ at $500 \mathrm{x} \mathrm{g}$ at $4^{\circ} \mathrm{C}$. The cells were finally cultured in DMEM supplemented with $10 \%$ FBS and $50 \mathrm{IU} / \mathrm{ml}$ penicillin/streptomycin and treated with or without $4 \mathrm{mM} \mathrm{VC}$ at $37^{\circ} \mathrm{C}$ for $48 \mathrm{~h}$. The present study was approved by the Huashan Hospital Institutional Review Board of Fudan University (permit no. 005/13) and written informed consent was obtained from each participant.

Annexin V/7-aminoactinomycin D (7-AAD) assay. Capan-1, PANC-1 cells and PBMCs were seeded in 6-well plates at $1 \times 10^{6}$ cells/well and treated with $4 \mathrm{mM} \mathrm{VC}$ at $37^{\circ} \mathrm{C}$ for $48 \mathrm{~h}$. The cells were then stained using Annexin V (BD Biosciences) at $4^{\circ} \mathrm{C}$ for $30 \mathrm{~min}$, followed by staining with 7-AAD (Invitrogen; Thermo Fisher Scientific, Inc.) for $5 \mathrm{~min}$ at room temperature. The percentage of apoptotic cells and necrotic cells was measured using a BD FACSCalibur flow cytometer (BD Biosciences) and analyses using FlowJo software (version 10; FlowJo LLC).

Wound healing assay. For cell migration assays, $1 \times 10^{6}$ cells/well were seeded in 6-well plates and incubated for $24 \mathrm{~h}$. A wound was created using a plastic $200-\mu \mathrm{l}$ tip and rinsed by PBS. The cells were incubated in DMEM containing $1 \% \mathrm{FBS}$ with or without $4 \mathrm{mM} \mathrm{VC}$. Images were obtained at 0 or $24 \mathrm{~h}$ post-wounding using an inverted light microscope (magnification, x100), and the scratch area was analyzed using the ImageJ wound healing tool (version $1.52 \mathrm{a}$; National Institutes of Health). The cell recovered area after $24 \mathrm{~h}$ was divided by the cell-free area at $0 \mathrm{~h}$ of the same well to obtain the percentage of wound closure.

Genomic DNA isolation and dot blot. Genomic DNA from Capan-1 and PANC-1 cells was extracted using TIANamp Genomic DNA kit (Tiangen Biotech Co., Ltd.), according to the manufacturer's instructions. The concentration of DNA was quantified using a NanoDrop (Thermo Fisher Scientific, Inc.). DNA samples were denatured and spotted onto a nitrocellulose membrane (GE Healthcare) and air-dried. DNA was fixed to the membrane by UV crosslinking for $15 \mathrm{~min}$. The membrane was then blocked with 5\% fat-free milk in 0.1\% TBS-Tween-20 (TBST) for $1 \mathrm{~h}$ at room temperature and incubated with the primary anti-5hmC antibody (cat. no. 40000; 1:500; Active Motif, Inc.) or anti-5mC antibody (cat. no. ab10805; 1:1,000; Abcam) at $4^{\circ} \mathrm{C}$ overnight. The membrane was incubated with a horseradish peroxidase-conjugated secondary antibody, anti-mouse IgG (cat. no. 7076S; 1:3,000; CST Biological Reagents Co., Ltd.) for $1 \mathrm{~h}$ at room temperature, washed with TBST, then detected using the ImageQuant LAS 4000 mini 
scanner (GE Healthcare) with Immobilon-ECL-Ultra-West ern-HRP-Substrate (EMD Millipore). The $5 \mathrm{hmC}$ and $5 \mathrm{mC}$ intensity was quantified using Image J software (version 1.52a; National Institutes of Health).

$R N A$ extraction and reverse transcription-quantitative PCR $(R T-q P C R)$. Total RNA from Capan-1 and PANC-1 cells was extracted using TRIzol ${ }^{\circledR}$ (Invitrogen; Thermo Fisher Scientific, Inc.) according to the manufacturer's protocol. RNA was reverse-transcribed using a Hifair II 1st Strand cDNA Synthesis SuperMix kit (Yeasen). qPCR was performed using the SYBR Green mix (Yeasen) on a 7500 Real-Time PCR system (Applied Biosystems; Thermo Fisher Scientific, Inc.) according to manufacturer's instructions. Quantitative gene amplification was performed using the following thermocycling conditions: 40 cycles of pre-denaturation at $95^{\circ} \mathrm{C}$ for $10 \mathrm{sec}$, annealing/extension at $60^{\circ} \mathrm{C}$ for $34 \mathrm{sec}$. Relative expression levels were normalized using the $2^{-\Delta \Delta \mathrm{Cq}}$ (32) method, and $\beta$-actin was used as an internal control. The primers used for RT-qPCR were as follows: $\beta$-actin forward, 5'-AGCGAGCATCCCCCAAAGTT-3' and reverse, 5'-GGG CACGAAGGCTCATCATT-3'; PHLPP2 forward, 5'-AGT CTTTACCATCCGCCTGC-3' and reverse, 5'-TGGAGT GTGCAACAAGGGT-3'; adenomatous polyposis coli (APC) forward, 5'-AAGCATGAAACCGGCTCACAT-3' and reverse, 5'-CATTCGTGTAGTTGAACCCTGA-3'; mitogen-activated protein kinase kinase 4 (MAP2K4) forward, 5'-CGGCTC TTCACTCCCAACAA-3' and reverse, 5'-GCTTTGCGTTTA CTTTGTGCC-3'; F-Box and WD repeat domain containing 7 forward, 5'-TGCAAAAGAGCCTCTACCACA-3' and reverse, 5'-CAAGCCCAGTGGTACTTGTAT-3'; helicase-like transcription factor (HLTF) forward, 5'-GAATTGTCTAGCTCC CGCCC-3' and reverse, 5'-TAGAAGATCCTTTCGCCC TGC-3'; HECT domain and ankyrin repeat containing E3 ubiquitin protein ligase 1 forward, 5'-GGAGTTGCCCGAGGA TAATGA-3' and reverse, 5'-TGCTGCAATGTGAAGCAA GC-3'; PLAG1 like zinc finger 1 forward (PLAGL1), 5'-TCC AGAACTTTCCAAGCGGG-3' and reverse, 5'-TCAGATGTG ACACGAGGCAG-3'; SNF2 histone linker PHD RING helicase (SHPRH) forward, 5'-ACAGGCTGCATCATTCGTGA-3' and reverse, 5'-TCCCTCGGGAAGAGTGAGAG-3'; TOP1 binding arginine/serine rich protein forward, 5'-GTCGAG GTGAGGGAGTGAAA-3' and reverse, 5'-AAGCCAGTA AGTCGTCGCAC-3'; AT-rich interactive domain-containing protein 1A (ARID1A) forward, 5'-GCCGAATCTCATGCC TTCCA-3' and reverse, 5'-GGCCGCTTGTAATTCTGC TGT-3'; and SWI/SNF related, matrix associated, actin dependent regulator of chromatin, subfamily a, member 2 (SMARCA2) forward, 5'-CTGTTTTGACCGGTTGCCTG-3' and reverse, 5'-CCAGTCAGTAGAGTAATGCTGC-3'.

$5 \mathrm{hmC}$ and $5 \mathrm{mC}$ assay. EpiMark ${ }^{\circledR} 5 \mathrm{hmC}$ and $5 \mathrm{mC}$ Analysis kit (New England Biolabs, Inc.) was used to quantify $5 \mathrm{hmC}$ and $5 \mathrm{mC}$ expression levels, according to the manufacturer's protocol. Genomic DNA was treated with T4 $\beta$-glucosyltransferase (New England Biolabs, Inc.) with or without UDP-Glucose substrate (New England Biolabs, Inc.) at $37^{\circ} \mathrm{C}$ overnight. Converted DNA was then digested with or without $\mathrm{MspI}$ and $\mathrm{HpaII}$ at $37^{\circ} \mathrm{C}$ overnight. $5 \mathrm{hmC}$ and $5 \mathrm{mC}$ expression levels were quantitatively analyzed using RT-qPCR with primers designed at peak regions containing the GGCC sequence that span one CCGG MspI/HpaII recognition site on PHLPP2. Primers used for RT-qPCR were as follows: PHLPP2 forward, 5'-GCTTGCCTGCCCTTGTTAAA3' and reverse, 5'-CAGTCTGTGTCCCCCATCTG-3'.

Small interfering RNA (siRNA) transfection. siRNA was designed by Suzhou Genepharma Co., Ltd. to downregulate PHLPP2 and TET2 expression levels. Capan-1 and PANC-1 cells were transfected with siRNAs using Lipofectamine ${ }^{\mathrm{TM}}$ 2000 (Invitrogen; Thermo Fisher Scientific, Inc.). A mixture of $100 \mathrm{nM}$ siRNA and Lipofectamine ${ }^{\circledR}$ were mixed for $20 \mathrm{~min}$ at room temperature, then added to the cells and incubated for $6 \mathrm{~h}$. The siRNA sequences were as follows: Control siRNA, 5'-UUCUCCGAACGUGUCACGUTT-3'; PHLPP2 siRNA, 5'-GCAACUUUCUGACUACUUUTT-3'; and TET2 siRNA, 5'-GGAUGUAAGUUUGCCAGAATT-3'. Subsequent experiments were performed $48 \mathrm{~h}$ post-transfection.

Western blot assays. Capan-1 and PANC-1 cells were serum starved overnight and treated with epidermal growth factor $(10 \mathrm{ng} / \mathrm{ml}$; PeproTech, Inc.) for $15 \mathrm{~min}$. Cells were lysed using RIPA lysis buffer (Beyotime Institute of Biotechnology). Following protein concentration analysis using a BCA protein assay kit (Beyotime Institute of Biotechnology), SDS-PAGE sample loading buffer (Beyotime Institute of Biotechnology) was added to the protein sample. Then, $50 \mu \mathrm{g}$ proteins were separated via 10\% SDS-PAGE (Epizyme) and transferred to nitrocellulose filter membranes (EMD Millipore). Subsequently, the membrane was blocked using $5 \%$ fat-free milk in TBST for $1 \mathrm{~h}$ at room temperature and incubated with the primary anti-phosphorylated-c-Raf (Ser338) antibody (cat. no. 9427S; 1:1,000; CST Biological Reagents Co., Ltd.), anti-c-Raf antibody (cat. no. 9422S; 1:1,000; CST) or anti-GAPDH antibody (cat. no. 5174S; 1:1,000; CST Biological Reagents Co., Ltd.) at $4^{\circ} \mathrm{C}$ overnight. The membrane was incubated with a horseradish peroxidase-conjugated secondary antibody, anti-Rabbit IgG (cat. no. 7074S; 1:5,000; CST Biological Reagents Co., Ltd.) for $1 \mathrm{~h}$ at room temperature, washed with TBST and then bands were detected using the ImageQuant LAS 4000mini scanner (GE Healthcare). The images were analyzed using Image $\mathbf{J}$ software (version 1.52a; National Institutes of Health).

Bioinformatics analysis. The RNA-Seq data and clinical information including overall survival data, disease free time, TNM stage and status of 178 patients of The Cancer Genome Atlas (TCGA) PAAD dataset were download the from UCSC Xena platform (https://xena.ucsc.edu/). Patient characteristics were listed in Table SI. The RPPA data of 116 PAAD patients were accessed and processed using the linkedomics (http://linkedomics.org/login.php) (33). For survival analysis, the median of SVCT1/2, GLUT1 and PHLPP2 expression was used to separate PAAD patients from TCGA database into the 'high' and 'low' groups. Survival analysis for overall survival (OS) and disease-free survival (DFS) was performed using the Kaplan Meier method and the log rank test was carried out using the R software 'survival' package (https://github.com/therneau/survival). The correlation between the expression of genes of TCGA PAAD dataset was analyzed by Pearson's correlation 
A
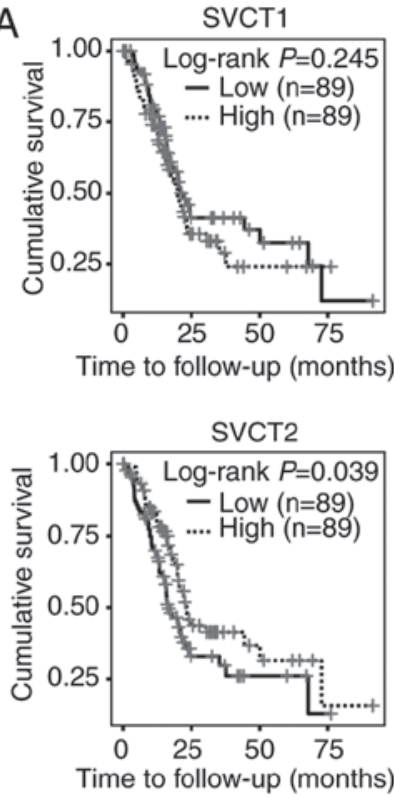

GLUT1

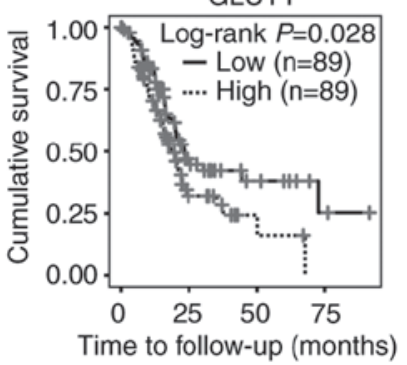

$\mathrm{B}$

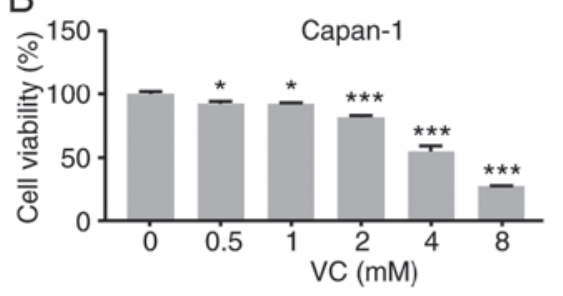

PANC-1

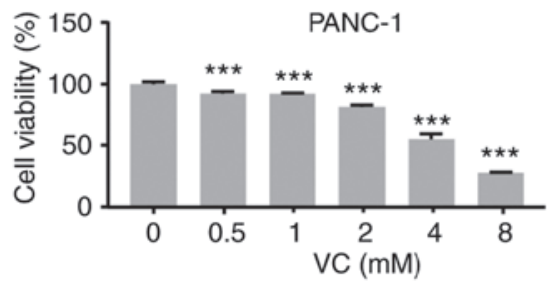

D

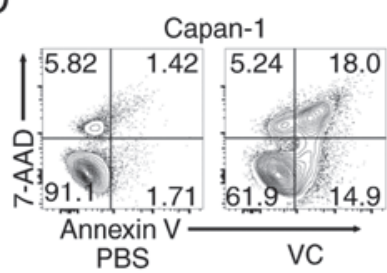

PANC-1

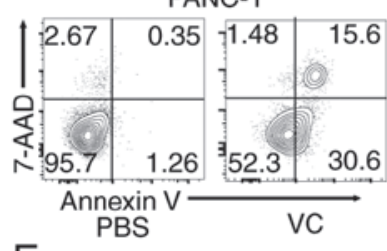

E

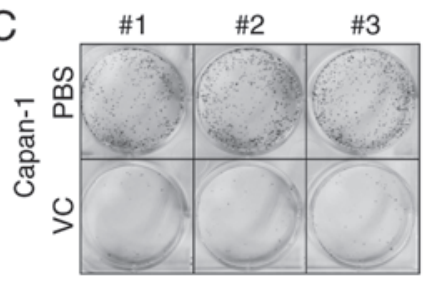

\#1
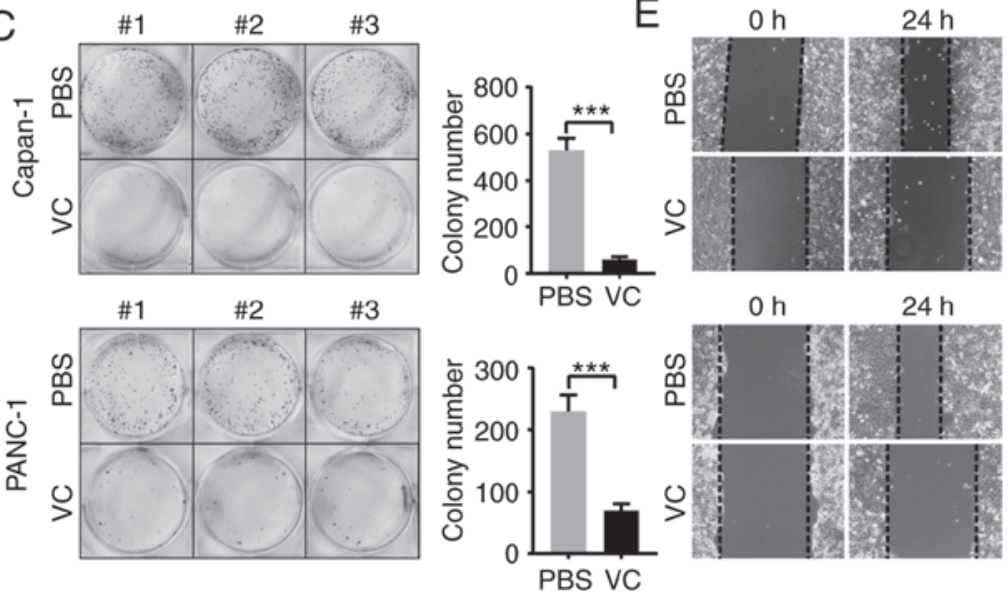
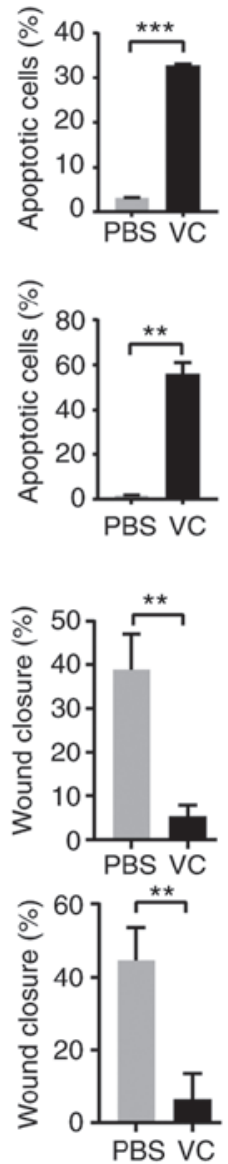

Figure 1. VC exhibits an antitumor effect in pancreatic cancer. (A) Kaplan-Meier analysis was used to analyze the associations between SVCT1, SVCT2 and GLUT1 expression levels and the overall survival rate of patients with pancreatic cancer. (B) Capan-1 or PANC-1 cells were exposed to various concentrations of VC for $48 \mathrm{~h}$, and cell viability was assessed using Cell Counting Kit- 8 assays. Data are presented as the percentage of the untreated control. ${ }^{*} \mathrm{P}<0.05$, ${ }^{* * *} \mathrm{P}<0.001$ vs. $0 \mathrm{mM}$ VC. (C) Colony formation assay was performed to measure cell proliferation. Capan-1 or PANC-1 cells were seeded into plates at a density of $1,000 /$ well and grown at $37^{\circ} \mathrm{C}$ for 10 days after exposure to $0.5 \mathrm{mM} \mathrm{VC}$ for $48 \mathrm{~h}$. Cell colonies were stained with $0.1 \%$ crystal violet (left), and colony numbers were quantified using ImageJ software (right). ${ }^{* * * *} \mathrm{P}<0.001$. (D) Capan-1 or PANC-1 cells were treated with $4 \mathrm{mM}$ VC for $48 \mathrm{~h}$, and then examined by flow cytometry to assess the levels of apoptosis. ${ }^{* *} \mathrm{P}<0.01,{ }^{* * *} \mathrm{P}<0.001$. (E) Following incubation for $24 \mathrm{~h}$, a scratch was made at the $0 \mathrm{~h}$ time point, then Capan-1 or PANC-1 cells were treated with $4 \mathrm{mM}$ VC for a further $24 \mathrm{~h}$ before images (magnification, $\mathrm{x} 100$ ) were obtained and data were quantified. ${ }^{* *} \mathrm{P}<0.01$. Data are presented as the mean \pm standard error of three independent experiments. SVCT, sodium-dependent VC transporter; VC, vitamin C; GLUT1, glucose transporter 1; 7-AAD, 7-aminoactinomycin D.

and curves were added according to the TIMER database algorithm (34). To identify he potential tumor suppressor target genes of VC, genes included in the TSGene 2.0 database (35) and positively correlated with TET2 and SVCT2 (Pearson's correlation $\geq 0.5$ ) were screened to generate a heat map using R software 'pheatmap' package (https://CRAN.R-project. org/package=pheatmap) and to validate experimentally.

Statistical analysis. Statistical significance was evaluated by an unpaired Student's t-tests or one-way ANOVA followed by Tukey's test for multiple comparisons using GraphPad Prism 7.0 software (GraphPad Software, Inc.). P<0.05 was considered to indicate a statistically significant difference.

\section{Results}

$V C$ exhibits antitumor effects in pancreatic cancer. To investigate the role of $\mathrm{VC}$ in the progression of pancreatic cancer, the associations between the expression levels of VC/DHA transporters (SVCT1, SVCT2 and GLUT1) and survival rates of patients with PDAC were identified. According to the Kaplan-Meier survival analysis of TCGA data (Fig. 1A), high expression levels of SVCT2 predicted good overall survival $(\mathrm{P}=0.039)$, while high expression of GLUT1 was associated with poor overall survival $(\mathrm{P}=0.028)$ of patients with PDAC. Patients with high or low expression of SVCT1 had no significant difference in the survival rate, which may due to the fact that SVCT2 is the predominant transporter of $\mathrm{VC}$ in the pancreas (36). The level of SVCT2 in patients with stage I disease was higher than that in patients with stage III or IV disease, and significantly higher than that in patients with stage II. However, there was no significant difference in DFS rate between patients with high or low expression levels of SVCT2 (Fig. S1). Since SVCT2 is an important VC transporter, these results indicated that VC may exhibit an antitumor effect in pancreatic cancer. In order to confirm the aforementioned hypothesis, human pancreatic cancer cells Capan-1 and PANC-1 were treated with various concentrations 
A

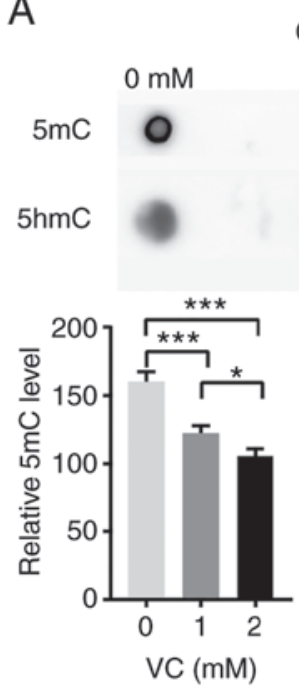

Capan-1

$1 \mathrm{mM}$

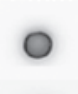

$2 \mathrm{mM}$

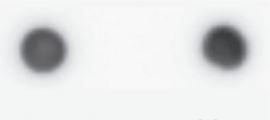

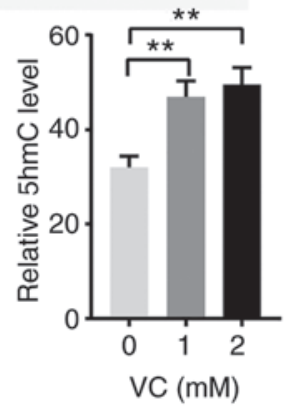
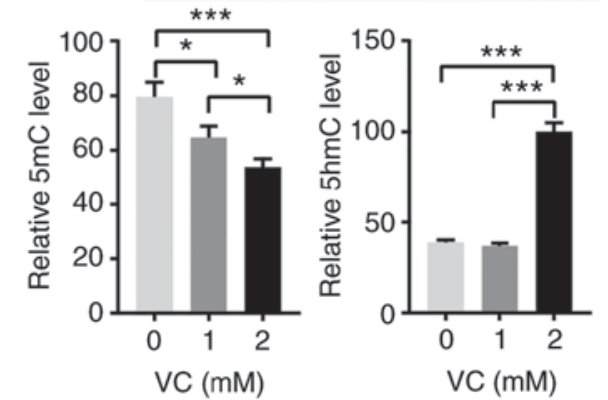

C
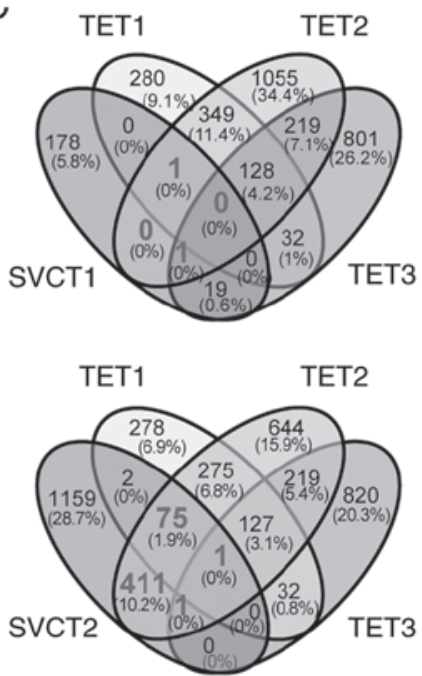

B
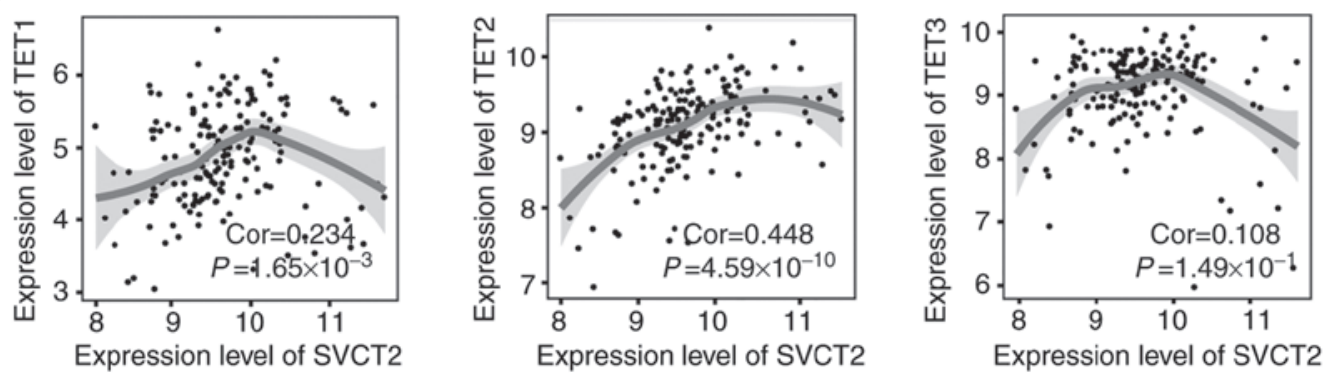

Figure 2. VC increases demethylation of pancreatic cancer cells through TET2. (A) Capan-1 or PANC-1 cells were exposed to increasing concentrations of $\mathrm{VC}$ for $24 \mathrm{~h}$. The genomic levels of $5 \mathrm{mC} / 5 \mathrm{hmC}$ were then assessed using dot blots. Data are presented as the mean \pm standard error of the mean of three independent experiments. ${ }^{*} \mathrm{P}<0.05,{ }^{* *} \mathrm{P}<0.01,{ }^{* * *} \mathrm{P}<0.001$. (B) The correlation between the expression of SVCT2 and TET1/2/3 was analyzed using Pearson's correlation and curves were added according to the TIMER database algorithm. (C) Venn diagram of the significantly correlated genes (correlation $>0.5$ ) with SVCT1/2 and TET1, 2 and 3. SVCT, sodium-dependent VC transporter; TET, ten-eleven translocation; VC, vitamin C; 5mC, 5-methylcytosine; 5hmC, 5-hydroxymethylcytosine.

of $\mathrm{VC}$ for $48 \mathrm{~h}$ in vitro. CCK-8 analyses demonstrated that $\mathrm{VC}$ treatment inhibited the proliferation of Capan-1 and PANC-1 cells in a concentration-dependent manner (Fig. 1B). Subsequently, colony formation assays were performed to further evaluate the role of VC on tumor cell growth. The ability of both Capan-1 and PANC-1 cells to form colonies was significantly impaired in response to VC treatment (Fig. 1C). Annexin V/7-AAD staining assays were utilized to determine whether VC treatment contributed to cell apoptosis. VC significantly induced cell apoptosis in both cell lines (Fig. 1D). Meanwhile, the effect of VC on cell migration was evaluated using wound healing assays. Since both Capan-1 and PANC-1 cells couldn't survive in serum-starved medium for $24 \mathrm{~h}, 1 \%$ FBS was used for the wound healing assays, which may be a limitation of the study. Following VC treatment, Capan-1 and PANC-1 cells had a significantly reduced migratory ability compared with those in the control group (Fig. 1E). To evaluate the safety of VC, the apoptosis of PBMCs, which were isolated from patients with pancreatic cancer and treated with or without VC, were analyzed using flow cytometry. The percentage of apoptotic PBMCs was not significantly increased following VC supplementation (Fig. S2), while VC could significantly induce apoptosis in PDAC cells (Fig. 1D). Therefore, the aforementioned data suggest that VC could inhibit the proliferation, growth and migration of tumor cells, while inducing tumor cell apoptosis. Collectively, the current findings suggested that VC may exhibit an antitumor effect in pancreatic cancer.

$V C$ increases demethylation of pancreatic cancer cells relying on TET2. Epigenetic regulation plays a crucial role in the development of PDAC; VC takes part in the epigenetic regulation, particularly in the conversion of $5 \mathrm{mC}$ to $5 \mathrm{hmC}$ by enhancing the catalytic activity of TET dioxygenases (5). Thus, the effect of $\mathrm{VC}$ on the global levels of $5 \mathrm{mC} / 5 \mathrm{hmC}$ was examined in both Capan-1 and PANC-1 cell lines using dot blot assays. A significant increase in global $5 \mathrm{hmC}$ levels was observed following VC treatment compared with PBS treatment, accompanied by a significant reduction in $5 \mathrm{mC}$ levels in both cell lines (Fig. 2A). The mRNA level of SVCT2 was positively correlated with that of TET1, TET2 and TET3 in tumor tissues from PDAC patients from TCGA database, with TET2 demonstrating the strongest correlation among the TET family (Fig. 2B). To further determine the downstream genes that may be regulated by TET 2 and VC, Pearson's correlation analysis was performed based on the gene expression levels from the PDAC dataset. A total of 488 genes were significantly correlated with the expression levels of TET2 and SVCT2, 
A

\begin{tabular}{|c|c|c|}
\hline 0.76 & 0.59 & APC \\
\hline 0.78 & 0.53 & SHPRH \\
\hline 0.77 & 0.52 & ARID1A \\
\hline 0.69 & 0.58 & HACE1 \\
\hline 0.65 & 0.51 & TOPORS \\
\hline 0.62 & 0.68 & PHLPP2 \\
\hline 0.57 & 0.75 & SMARCA \\
\hline 0.55 & 0.71 & MAP2K4 \\
\hline 0.53 & 0.55 & PLAGL1 \\
\hline 0.59 & 0.64 & FBXW7 \\
\hline 0.58 & 0.59 & HLTF \\
\hline
\end{tabular}

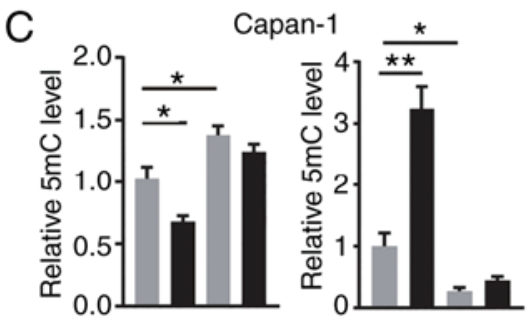

PANC-1
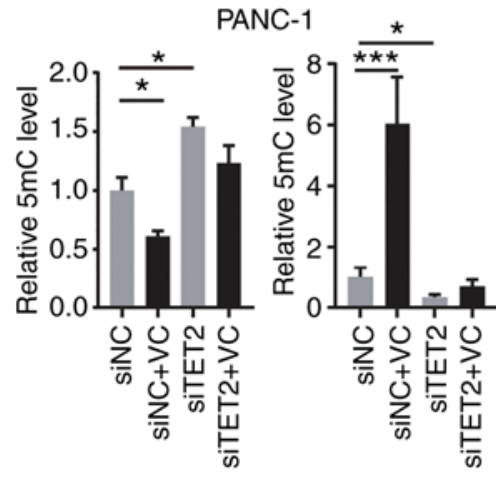
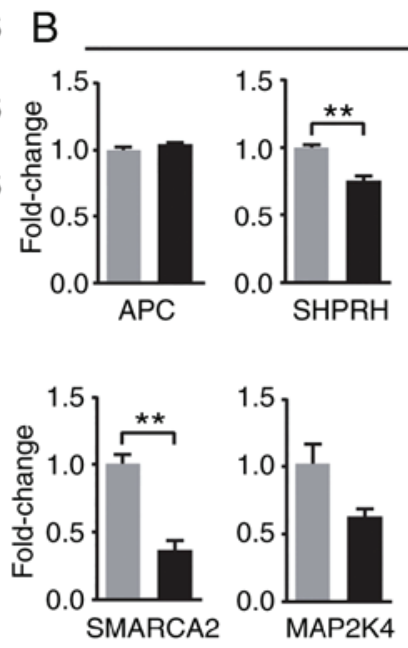

Capan-1
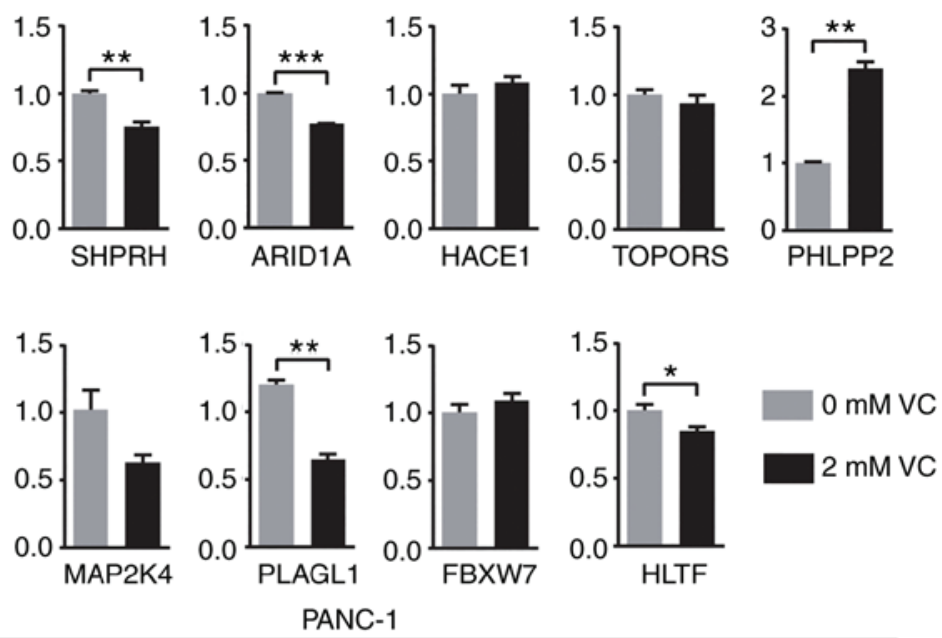

PANC-1
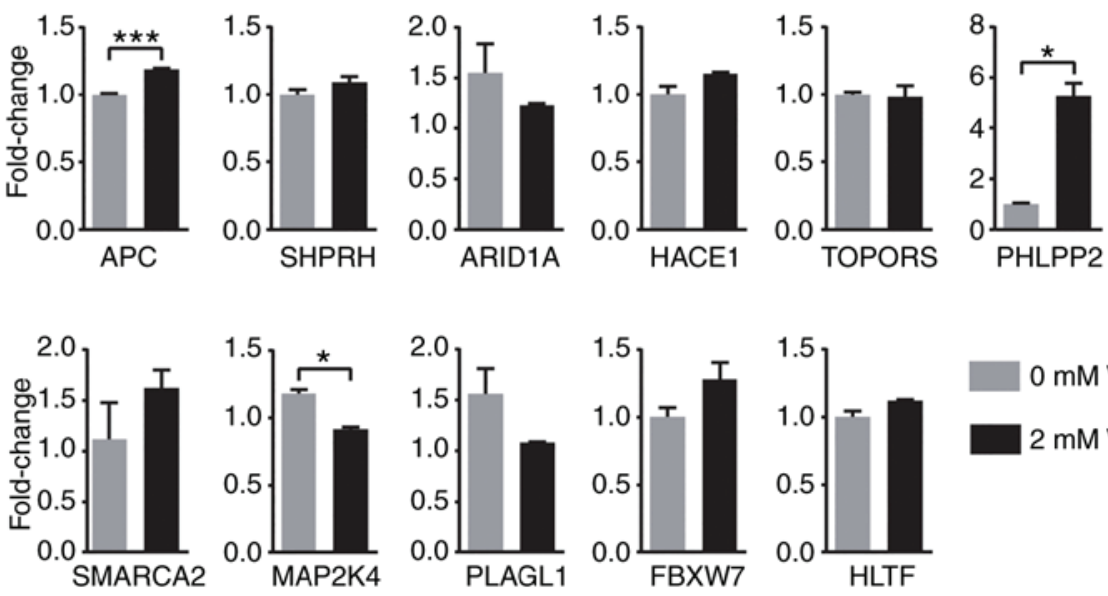

$0 \mathrm{mM}$ VC

$2 \mathrm{mM}$ VC

Figure 3. VC specifically upregulates PHLPP2 through DNA demethylation. (A) Heatmap of the correlation between tumor suppressor genes and SVCT2/TET2 (B) Quantitative changes in the mRNA expression levels of tumor suppressor genes in Capan-1 or PANC-1 cells with VC treatment. (C) The levels of $5 \mathrm{mC} / 5 \mathrm{hmC}$ in the PHLPP2 promoter of siNC/siPHLPP2-treated PDAC cells were detected following VC supplementation. Data are presented as the mean \pm standard error of the mean of three independent experiments. ${ }^{*} \mathrm{P}<0.05,{ }^{* *} \mathrm{P}<0.01,{ }^{* * * *} \mathrm{P}<0.001$. PHLPP2, PH domain leucine-rich repeat protein phosphatase 2; si, small interfering RNA; VC, vitamin C; NC, negative control; 5mC, 5-methylcytosine; 5hmC, 5-hydroxymethylcytosine; SVCT, sodium-dependent VC transporter; TET2, ten-eleven translocation 2; APC, adenomatous polyposis coli; SHPRH, SNF2 histone linker PHD RING helicase; ARID1A, AT-rich interactive domain-containing protein 1A; HACE1, HECT domain and ankyrin repeat containing E3 ubiquitin protein ligase 1; TOPORS, TOP1 binding arginine/serine rich protein; SMARCA2, SWI/SNF related, matrix associated, actin dependent regulator of chromatin, subfamily a, member 2; MAP2K4, mitogen-activated protein kinase kinase 4; PLAGL1, PLAG1 like zinc finger 1; FBXW7, F-Box and WD repeat domain containing 7; HLTF, helicase-like transcription factor.

while only 78 and 2 genes were positively correlated with SVCT2 for TET1 and TET3, respectively (Fig. 2C). This suggests $\mathrm{VC}$ may increase the expression level of $5 \mathrm{hmC}$ in pancreatic cancer cells, which mainly relies on TET2.

VC specifically upregulates PHLPP2 through DNA demethylation. To seek the potential target genes of VC, the TSGene 2.0 database, an updated gene set of tumor suppressor genes, was used to screen the genes that may be involved in the antitumor activity of VC. Initially, the present study screened for genes that positively correlated with TET2 and SVCT2 (Pearson's correlation $\geq 0.5$ ). Then, tumor suppressor genes identified by the TSGene database within these genes were selected, resulting in 36 genes. Among the 36 genes, 11 genes were selected based on previous reports associated with the progression of PDAC (37-41) (Fig. 3A). RT-qPCR was used to validate the expression levels of these 11 genes after $\mathrm{VC}$ treatment in both Capan-1 and PANC-1 cell lines. Following VC treatment, SHPRH, ARID1A, SMARCA2, PLAGL1 and HLTF were significantly decreased, and only PHLPP2 was significantly increased in Capan-1. Following treatment of PANC-1 cells with VC, MAP2K4 was significantly downregulated, and PHLPP2 and APC were significantly upregulated. Notably, only PHLPP2 exhibited a significant increase in both cell lines, with a 2.4-fold change in Capan-1 and 5.3-fold change in PANC-1 following exposure to VC (Fig. 3B). To further investigate whether the upregulation of PHLPP2 resulted from a VC-stimulated increase in TET2-dependent DNA 
A

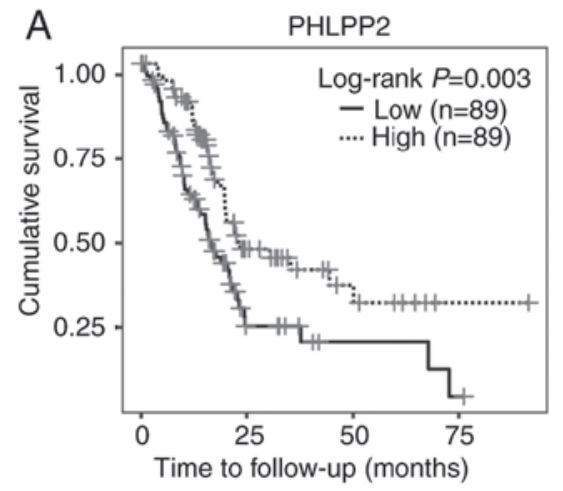

C

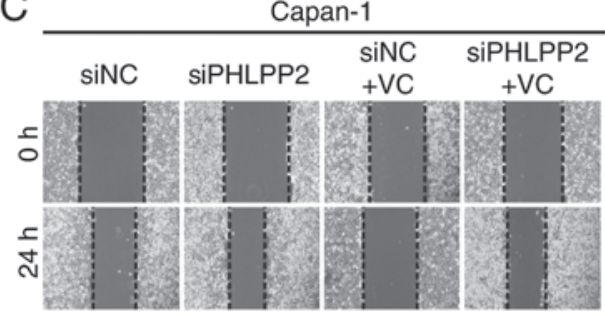

B

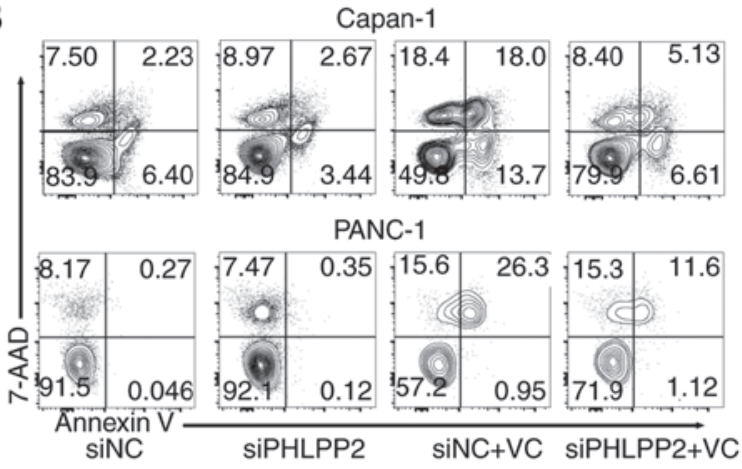

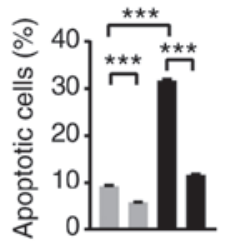

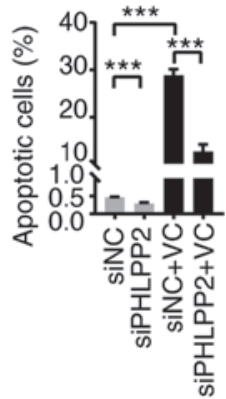

PANC-1
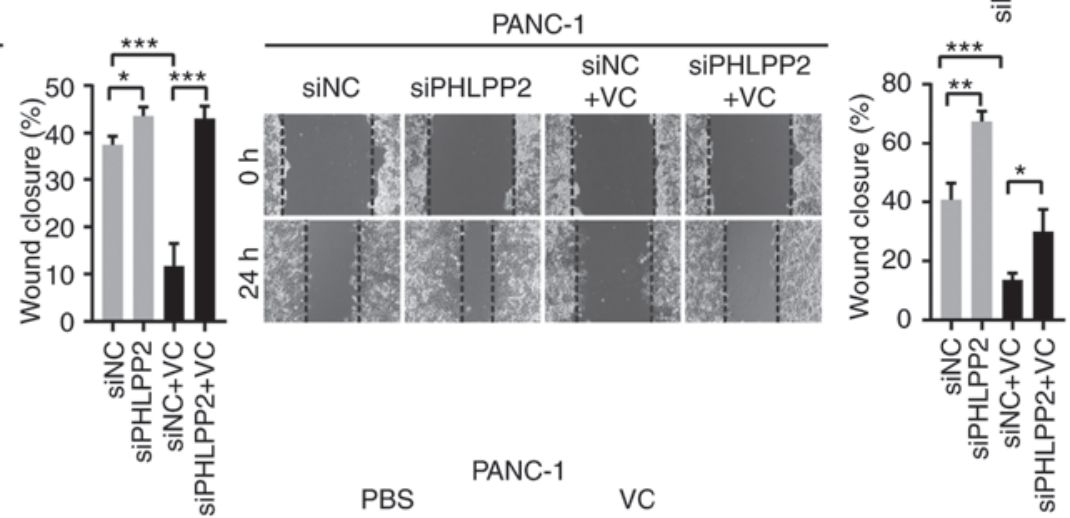

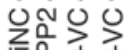
责船高
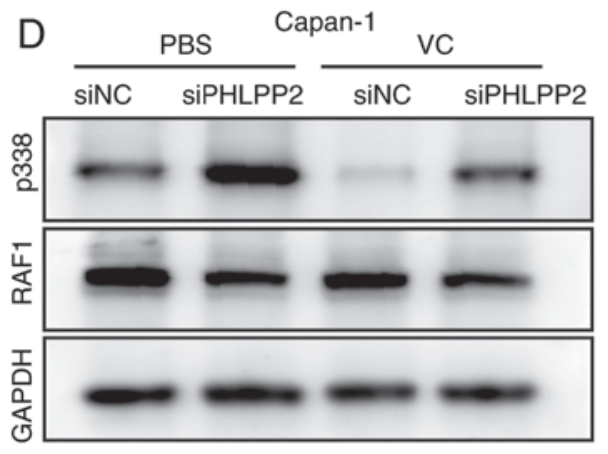
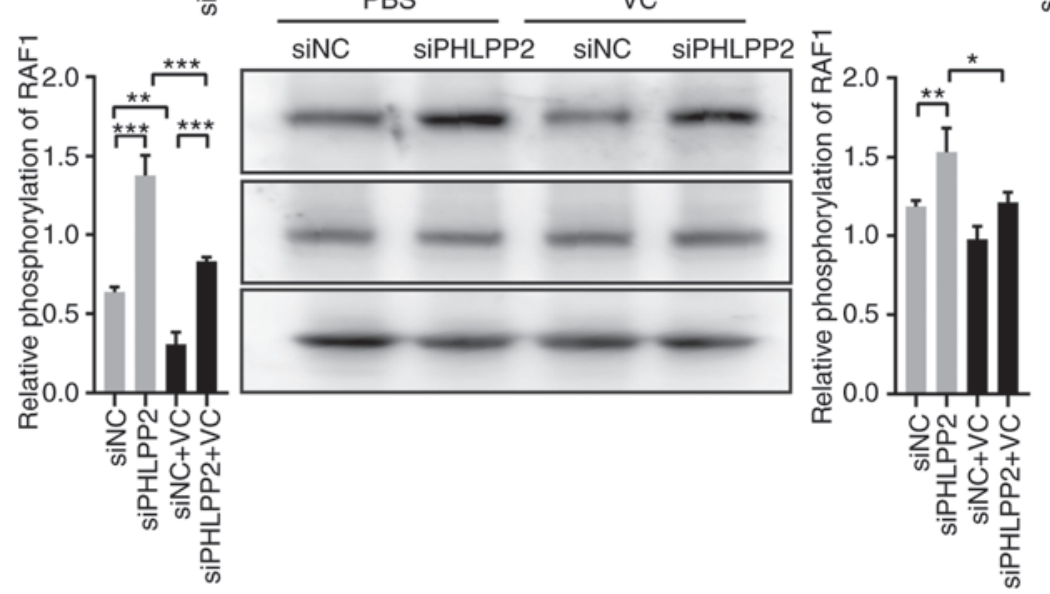

Figure 4. Antitumor effect of VC partially depends on PHLPP2. (A) Survival analysis of PHLPP2 in patients with PDAC. (B) Following PHLPP2-knockdown, Capan-1 or PANC-1 cells were treated with $4 \mathrm{mM}$ VC, and apoptosis was assessed using Annexin V/7AAD staining. (C) The migratory ability of the cells was assessed using wound healing assays. (D) siNC and siPHLPP2-treated PDAC cells were serum starved overnight and treated with epidermal growth factor $(10 \mathrm{ng} / \mathrm{ml})$ for $15 \mathrm{~min}$, and cell lysates were analyzed for phosphorylated and total RAF1 expression levels. Data are presented as the mean \pm standard error of the mean of three independent experiments. ${ }^{*} \mathrm{P}<0.05,{ }^{* *} \mathrm{P}<0.01,{ }^{* * *} \mathrm{P}<0.001$. PHLPP2, PH domain leucine-rich repeat protein phosphatase 2 ; si, small interfering RNA; VC, vitamin C; NC, negative control; 7-AAD, 7-aminoactinomycin D.

demethylation, a promoter methylation assay was utilized to measure the expression levels of $5 \mathrm{mC} / 5 \mathrm{hmC}$ at the PHLPP2 promoter. VC supplementation significantly increased the percentage of $5 \mathrm{hmC}$, accompanied with a decrease in $5 \mathrm{mC}$ at the PHLPP2 promoter region. Knocking down the expression levels of TET 2 by siRNA (Fig. S3A), led to a decrease in $5 \mathrm{hmC}$ levels and increase in $5 \mathrm{mC}$ levels at the PHLPP2 promoter, while VC supplementation could not reverse the reduction (Fig. 3C). Thus, the current findings suggested that VC could upregulate the PHLPP2 expression levels by enhancing PHLPP2 promoter demethylation, depending on TET2.
Antitumor effect of VC partially depends on PHLPP2.PHLPP2 is a tumor suppressor gene that has been reported to inhibit progression of various cancer types, including breast, prostate, bladder and lung cancer (42). Similarly, as shown in the Kaplan-Meier analysis, patients with high PHLPP2 expression levels had a significantly higher overall survival rate compared with those with low PHLPP2 levels ( $\mathrm{P}=0.003$; Fig. 4A). To confirm whether PHLPP2 plays a major role in the inhibitory effect of VC on PDAC, PHLPP2 expression in Capan-1 and PANC-1 cells was knocked down using siRNAs (Fig. S3B), which were then subjected to $\mathrm{VC}$ treatment. VC-induced cell 
apoptosis was significantly reduced in response to PHLPP2 silencing; however, VC-induced cell necrosis was reduced by knockdown of the expression of PHLPP2 only in Capan-1 cells (Figs. 4B and S4). Meanwhile, VC-mediated reduction of the migration in both cell lines was partially restored through silencing of PHLPP2 (Fig. 4C). Furthermore, western blot assays were used to detect the phosphorylation levels of Raf1, which has been reported to be dephosphorylated by PHLPP2 at S338 (43). PHLPP2-knockdown resulted in a significant increase in Raf1 phosphorylation, with VC able to attenuate the increase (Fig. 4D). The RPPA data of patients with PDAC from TCGA database also demonstrated that PHLLP2 exhibited a significant negative correlation with the levels of phosphorylated Raf1 (Pearson's correlation, -0.249; $\mathrm{P}=6.91 \times 10^{-3}$ ), while SVCT2 was also negatively correlated with the levels of C-Raf pS338 (Pearson's correlation, $-0.162 ; \mathrm{P}=8.16 \times 10^{-2}$; Fig. S5). Collectively, the current data demonstrated that the antitumor effect of VC was partially dependent on PHLPP2.

\section{Discussion}

VC treatment has been reported to exhibit an antitumor effect in cancer treatment; however, there is a lack of convincing clinical evidence, particularly in pancreatic cancer $(19,23,44)$. The present study investigated the association between the epigenetic regulation of $\mathrm{VC}$ and pancreatic cancer, which demonstrated that $\mathrm{VC}$ exerted its antitumor activity partially by upregulating PHLPP2 expression levels through DNA demethylation. The 5hmC levels of PHLPP2 may act as a biomarker and an epigenetic target of $\mathrm{VC}$ for pancreatic cancer therapy.

The mechanisms of action underlying the antitumor effect of VC include oxidative stress and epigenetic regulation, with most previous studies predominantly focusing on the former $(24,25)$. However, Ge et al $(45)$ have found that oxidation-resistant $\mathrm{VC}$ derivatives, which lack the ability to induce oxidative stress in tumor cells, still exhibit antitumor efficacy. Previously, epigenetic regulation has gained increasing attention as a supplementary mechanism for the action of $\mathrm{VC}$ against tumors $(16,17,45,46)$. It has been well established that epigenetic dysregulation is recognized as a hallmark in the development of multiple tumor types, such as breast, liver, lung and prostate cancer $(11,47,48)$. For example, the levels of $5 \mathrm{hmC}$ were found to be significantly decreased, accompanied with a $5 \mathrm{mC}$ increase in various cancer types, including PDAC, which may lead to the silencing of tumor suppressor genes $(47,48)$. Since VC serves as a co-factor of TET2 and is indispensable for its optimal catalytic activity, high dose VC treatment may enhance the activity of TET2 leading to an increase in the levels of $5 \mathrm{hmC}$ in tumors (45). Consistent with the aforementioned findings, the present study demonstrated that VC could reverse the loss of 5hmC through TET2, and identified an increase in $5 \mathrm{hmC}$ levels in the promoter region of the tumor suppressor gene PHLPP2.

The PHLPP family consists of PHLPP1 and PHLPP2. PHLPP2 can dephosphorylate AKT and Raf1, resulting in the induction of apoptosis and the inhibition of migration, which is consistent with the current results $(49,50)$. PHLPP2 has been reported to be downregulated in various tumor types, including PDAC (51), and in vitro studies have demonstrated that overexpression of PHLPP2 can inhibit tumor growth in prostate, bladder and endometrial cancer $(50,52)$. The present study confirmed that PHLPP2 re-expression could inhibit pancreatic cancer cells. Furthermore, the participation of VC-induced epigenetic reprogramming was also identified in PHLPP2 re-expression.

Due to the paradoxical conclusions in clinical trials of $\mathrm{VC}$ treatment, biomarkers are required for the proper selection of patients that are sensitive to VC-based therapies, to substantially improve the clinical efficacy of VC $(44,46)$. According to the current results, several conclusions regarding biomarkers could be made. For example, patients with low expression levels of SVCT2 may not benefit from VC treatment because VC cannot be effectively transported into tumor cells (53). In addition, patients with low levels of $5 \mathrm{hmC}$ in tumor tissues may be more responsive to $\mathrm{VC}$ treatment. Specifically, in $\mathrm{PDAC}$, low expression levels of $5 \mathrm{hmC}$ in the promotor region of PHLPP2 in tumor tissues may be an ideal indicator for $\mathrm{VC}$ treatment.

In conclusion, the present study identified that SVCT2 is positively correlated with the prognosis of patients with PDAC. VC treatment can directly inhibit human pancreatic tumor cells, which is partially dependent on the upregulation of PHLPP2 through DNA demethylation. The current results suggest a novel epigenetic regulatory mechanism for the antitumor effect of VC and provide a theoretical basis for using PHLPP2 as a novel biomarker and epigenetic target in VC treatment of pancreatic cancer.

\section{Acknowledgements}

The authors wish to thank to Ms. Diana Tseng (Fudan University, Shanghai, China) for critically reading the manuscript.

\section{Funding}

This work was supported by the National Natural Science Foundation of China (grant nos. 81830080, 81870375, 81870456 and 81600438) and the Shanghai Rising-Star Program (grant no. 18QA1401000).

\section{Availability of data and materials}

All data generated or analyzed during this study are included in this published article.

\section{Authors' contributions}

FL and JL designed the research. LC, HS, ZL, HC, WZ, YL and WL performed experiments and analyzed the data. FL, JL, LC and HS wrote manuscript. LC, HS, ZL and HC contributed equally to the work. FL and JL revised the manuscript and jointly supervised the work. All authors read and approved the final manuscript.

\section{Ethics approval and consent to participate}

The present study was approved by the Huashan Hospital Institutional Review Board of Fudan University (Shanghai, 
China; permit no. 005/13) and written informed consent was obtained from each participant.

\section{Patient consent for publication}

Not applicable.

\section{Competing interests}

The authors declare that they have no competing interests.

\section{References}

1. Siegel RL, Miller KD and Jemal A: Cancer statistics, 2019. CA Cancer J Clin 69: 7-34, 2019.

2. Siegel R, Naishadham D and Jemal A: Cancer statistics, 2013. CA Cancer J Clin 63: 11-30, 2013.

3. Lee S, Kim J, Jung S, Li C, Yang Y, Kim KI, Lim JS, Kim Y, Cheon CI and Lee MS: SIAH1-induced p34SEI-1 polyubiquitination/degradation mediates p53 preferential vitamin C cytotoxicity. Int J Oncol 46: 1377-1384, 2015

4. Vera JC, Rivas CI, Fischbarg J and Golde DW: Mammalian facilitative hexose transporters mediate the transport of dehydroascorbic acid. Nature 364: 79-82, 1993.

5. Tsukaguchi H, Tokui T, Mackenzie B, Berger UV, Chen XZ, Wang Y, Brubaker RF and Hediger MA: A family of mammalian $\mathrm{Na}$--dependent L-ascorbic acid transporters. Nature 399: 70-75, 1999.

6. McCarty MF: Expression and/or activity of the SVCT2 ascorbate transporter may be decreased in many aggressive cancers, suggesting potential utility for sodium bicarbonate and dehydroascorbic acid in cancer therapy. Med Hypotheses 81: 664-670, 2013.

7. Kuiper C and Vissers MC: Ascorbate as a co-factor for fe- and 2-oxoglutarate dependent dioxygenases: Physiological activity in tumor growth and progression. Front Oncol 4: 359, 2014.

8. Mastrangelo D, Pelosi E, Castelli G, Lo-Coco F and Testa U: Mechanisms of anti-cancer effects of ascorbate: Cytotoxic activity and epigenetic modulation. Blood Cells Mol Dis 69: 57-64, 2018.

9. Navada SC, Steinmann J, Lübbert M and Silverman LR: Clinical development of demethylating agents in hematology. J Clin Invest 124: 40-46, 2014.

10. Tahiliani M, Koh KP, Shen Y, Pastor WA, Bandukwala H, Brudno Y, Agarwal S, Iyer LM, Liu DR, Aravind L and Rao A: Conversion of 5-methylcytosine to 5-hydroxymethylcytosine in mammalian DNA by MLL partner TET1. Science 324: 930-935, 2009.

11. Ushijima T: Cancer epigenetics: Now harvesting fruit and seeding for common diseases. Biochem Biophys Res Commun 455: 1-2, 2014.

12. Rasmussen KD and Helin K: Role of TET enzymes in DNA methylation, development, and cancer. Genes Dev 30: 733-750, 2016.

13. Woods BA and Levine RL: The role of mutations in epigenetic regulators in myeloid malignancies. Immunol Rev 263: 22-35, 2015.

14. Minor EA, Court BL, Young JI and Wang G: Ascorbate induces ten-eleven translocation (Tet) methylcytosine dioxygenase-mediated generation of 5-hydroxymethylcytosine. J Biol Chem 288 : 13669-13674, 2013.

15. Yin R, Mao SQ, Zhao B, Chong Z, Yang Y, Zhao C, Zhang D, Huang H, Gao J, Li Z, et al: Ascorbic acid enhances Tet-mediated 5 -methylcytosine oxidation and promotes DNA demethylation in mammals. J Am Chem Soc 135: 10396-10403, 2013.

16. Blaschke K, Ebata KT, Karimi MM, Zepeda-Martinez JA, Goyal P, Mahapatra S, Tam A, Laird DJ, Hirst M, Rao A, et al: Vitamin C induces Tet-dependent DNA demethylation and a blastocyst-like state in ES cells. Nature 500: 222-226, 2013.

17. Cimmino L, Dolgalev I, Wang Y, Yoshimi A, Martin GH, Wang J, Ng V, Xia B, Witkowski MT, Mitchell-Flack M, et al: Restoration of TET2 function blocks aberrant self-renewal and leukemia progression. Cell 170: 1079-1095.e20, 2017.

18. Lin JR, Qin HH, Wu WY, He SJ and Xu JH: Vitamin C protects against UV irradiation-induced apoptosis through reactivating silenced tumor suppressor genes p21 and p16 in a Tet-dependent DNA demethylation manner in human skin cancer cells. Cancer Biother Radiopharm 29: 257-264, 2014
19. Gillberg L, $\varnothing$ rskov AD, Liu M, Harsløf LBS, Jones PA and Grønbaek K: Vitamin C-A new player in regulation of the cancer epigenome. Semin Cancer Biol 51: 59-67, 2018

20. Ngo B, Van Riper JM, Cantley LC and Yun J: Targeting cancer vulnerabilities with high-dose vitamin C. Nat Rev Cancer 19: 271-282, 2019.

21. Takemura Y, Satoh M, Satoh K, Hamada H, Sekido Y and Kubota S: High dose of ascorbic acid induces cell death in mesothelioma cells. Biochem Biophys Res Commun 394: 249-253, 2010.

22. Reddy VG, Khanna N and Singh N: Vitamin C augments chemotherapeutic response of cervical carcinoma HeLa cells by stabilizing P53. Biochem Biophys Res Commun 282: 409-415, 2001.

23. Cha J, Roomi MW, Ivanov V, Kalinovsky T, Niedzwiecki A and Rath M: Ascorbate supplementation inhibits growth and metastasis of B16FO melanoma and 4T1 breast cancer cells in vitamin C-deficient mice. Int J Oncol 42: 55-64, 2013.

24. Baek MW, Cho HS, Kim SH, Kim WJ and Jung JY: Ascorbic acid induces necrosis in human laryngeal squamous cell carcinoma via ROS, PKC, and calcium signaling. J Cell Physiol 232: 417-425, 2017.

25. Su X, Shen Z, Yang Q, Sui F, Pu J, Ma J, Ma S, Yao D, Ji M and Hou P: Vitamin C kills thyroid cancer cells through ROS-dependent inhibition of MAPK/ERK and PI3K/AKT pathways via distinct mechanisms. Theranostics 9: 4461-4473, 2019.

26. Polireddy K, Dong R, Reed G, Yu J, Chen P, Williamson S, Violet PC, Pessetto Z, Godwin AK, Fan F, et al: High dose parenteral ascorbate inhibited pancreatic cancer growth and metastasis: Mechanisms and a phase I/IIa study. Sci Rep 7: 17188, 2017.

27. Welsh JL, Wagner BA, van't Erve TJ, Zehr PS, Berg DJ, Halfdanarson TR, Yee NS, Bodeker KL, Du J, Roberts LJ II, et al: Pharmacological ascorbate with gemcitabine for the control of metastatic and node-positive pancreatic cancer (PACMAN): Results from a phase I clinical trial. Cancer Chemother Pharmacol 71: 765-775, 2013.

28. Hoffer LJ, Levine M, Assouline S, Melnychuk D, Padayatty SJ, Rosadiuk K, Rousseau C, Robitaille L and Miller WH Jr: Phase I clinical trial of i.v. ascorbic acid in advanced malignancy. Ann Oncol 19: 1969-1974, 2008.

29. Carr AC, Vissers MC and Cook JS: The effect of intravenous vitamin $\mathrm{C}$ on cancer- and chemotherapy-related fatigue and quality of life. Front Oncol 4: 283, 2014.

30. Espey MG, Chen P, Chalmers B, Drisko J, Sun AY, Levine M and Chen Q: Pharmacologic ascorbate synergizes with gemcitabine in preclinical models of pancreatic cancer. Free Radic Biol Med 50: 1610-1619, 2011.

31. Drisko JA, Serrano OK, Spruce LR, Chen Q and Levine M: Treatment of pancreatic cancer with intravenous vitamin $\mathrm{C}$ : A case report. Anticancer Drugs 29: 373-379, 2018.

32. Livak KJ and Schmittgen TD: Analysis of relative gene expression data using real-time quantitative PCR and the 2(-Delta Delta C(T)) method. Methods 25: 402-408, 2001.

33. Vasaikar SV, Straub P, Wang J and Zhang B: LinkedOmics: Analyzing multi-omics data within and across 32 cancer types. Nucleic Acids Res 46 (D1): D956-D963, 2018.

34. Li T, Fan J, Wang B, Traugh N, Chen Q, Liu JS, Li B and Liu XS: TIMER: A web server for comprehensive analysis of tumor-infiltrating immune cells. Cancer Res 77: e108-e110, 2017.

35. Zhao M, Kim P, Mitra R, Zhao J and Zhao Z: TSGene 2.0: An updated literature-based knowledgebase for tumor suppressor genes. Nucleic Acids Res 44 (D1): D1023-D1031, 2016.

36. Subramanian VS, Srinivasan P and Said HM: Uptake of ascorbic acid by pancreatic acinar cells is negatively impacted by chronic alcohol exposure. Am J Physiol Cell Physiol 311: C129-C135, 2016.

37. Waddell N, Pajic M, Patch AM, Chang DK, Kassahn KS, Bailey P, Johns AL, Miller D, Nones K, Quek K, et al: Whole genomes redefine the mutational landscape of pancreatic cancer. Nature 518: 495-501, 2015.

38. Smith AJ, Wen YA, Stevens PD, Liu J, Wang C and Gao T: PHLPP negatively regulates cell motility through inhibition of Akt activity and integrin expression in pancreatic cancer cells. Oncotarget 7: 7801-7815, 2016.

39. Zhang Z, Wang F, Du C, Guo H, Ma L, Liu X, Kornmann M, Tian X and Yang Y: BRM/SMARCA2 promotes the proliferation and chemoresistance of pancreatic cancer cells by targeting JAK2/STAT3 signaling. Cancer Lett 402: 213-224, 2017. 
40. Niu N, Lu P, Yang Y, He R, Zhang L, Shi J, Wu J, Yang M Zhang ZG, Wang LW, et al: Loss of Setd2 promotes Kras-induced acinar-to-ductal metaplasia and epithelia-mesenchymal transition during pancreatic carcinogenesis. Gut: Jul 11, 2019 (Epub ahead of print).

41. Grant RC, Selander I, Connor AA, Selvarajah S, Borgida A, Briollais L, Petersen GM, Lerner-Ellis J, Holter S and Gallinger S: Prevalence of germline mutations in cancer predisposition genes in patients with pancreatic cancer. Gastroenterology 148: 556-564, 2015.

42. Newton AC and Trotman LC: Turning off AKT: PHLPP as a drug target. Annu Rev Pharmacol Toxicol 54: 537-558, 2014.

43. Li X, Stevens PD, Liu J, Yang H, Wang W, Wang C, Zeng Z, Schmidt MD, Yang M, Lee EY and Gao T: PHLPP is a negative regulator of RAF1, which reduces colorectal cancer cell motility and prevents tumor progression in mice. Gastroenterology 146: 1301-1312.e1-e10, 2014.

44. Shenoy N, Creagan E, Witzig T and Levine M: Ascorbic acid in cancer treatment: Let the phoenix fly. Cancer Cell 34: 700-706, 2018.

45. Ge G, Peng D, Xu Z, Guan B, Xin Z, He Q, Zhou Y, Li X, Zhou L and $\mathrm{Ci} \mathrm{W}$ : Restoration of 5-hydroxymethylcytosine by ascorbate blocks kidney tumour growth. EMBO Rep 19: pii: e45401, 2018.

46. Cimmino L, Neel BG and Aifantis I: Vitamin C in stem cell reprogramming and cancer. Trends Cell Biol 28: 698-708, 2018.

47. Yang H, Liu Y, Bai F, Zhang JY, Ma SH, Liu J, Xu ZD, Zhu HG, Ling ZQ, Ye D, et al: Tumor development is associated with decrease of TET gene expression and 5-methylcytosine hydroxylation. Oncogene 32: 663-669, 2013.
48. Huang Y and Rao A: Connections between TET proteins and aberrant DNA modification in cancer. Trends Genet 30: 464-474, 2014.

49. Huang C, Liao X, Jin H, Xie F, Zheng F, Li J, Zhou C, Jiang G, Wu XR and Huang C: MEG3, as a Competing endogenous RNA, binds with miR-27a to promote PHLPP2 protein translation and impairs bladder cancer invasion. Mol Ther Nucleic Acids 16: 51-62, 2019.

50. Liu J, Eckert MA, Harada BT, Liu SM, Lu Z, Yu K, Tienda SM, Chryplewicz A, Zhu AC, Yang Y, et al: $\mathrm{m}^{6} \mathrm{~A}$ mRNA methylation regulates AKT activity to promote the proliferation and tumorigenicity of endometrial cancer. Nat Cell Biol 20: 1074-1083, 2018.

51. Nitsche C, Edderkaoui M, Moore RM, Eibl G, Kasahara N, Treger J, Grippo PJ, Mayerle J, Lerch MM and Gukovskaya AS: The phosphatase PHLPP1 regulates Akt2, promotes pancreatic cancer cell death, and inhibits tumor formation. Gastroenterology 142: 377-387.e1-e5, 2012.

52. Nowak DG, Katsenelson KC, Watrud KE, Chen M, Mathew G, D'Andrea VD, Lee MF, Swamynathan MM, Casanova-Salas I, Jibilian MC, et al: The PHLPP2 phosphatase is a druggable driver of prostate cancer progression. J Cell Biol 218: 1943-1957, 2019.

53. Kuiper C, Vissers MC and Hicks KO: Pharmacokinetic modeling of ascorbate diffusion through normal and tumor tissue. Free Radic Biol Med 77: 340-352, 2014. 